Western University

Scholarship@Western

Health and Rehabilitation Sciences Publications Health and Rehabilitation Sciences Program

2020

Supports for Migrant Farmworkers: Tensions in (In)access and (In)action

\author{
Susana Caxaj \\ scaxaj@uwo.ca \\ Amy Cohen \\ Okanagan College, acohen@okanagan.bc.ca \\ Sarah Marsden \\ Thompson Rivers University, smarsden@tru.ca
}

Follow this and additional works at: https://ir.lib.uwo.ca/hrspub

Part of the Human Geography Commons, Latin American Studies Commons, Other Legal Studies Commons, Psychiatric and Mental Health Nursing Commons, Public Health and Community Nursing Commons, Public Health Education and Promotion Commons, Rehabilitation and Therapy Commons, and the Social Work Commons

Citation of this paper:

Caxaj, S., Cohen, A. and Marsden, S. (2020), "Supports for migrant farmworkers: tensions in (in)access and (in)action", International Journal of Migration, Health and Social Care, Vol. 16 No. 4, pp. 557-571. https://doi.org/10.1108/IJMHSC-03-2020-0017 
Western University

Scholarship@Western

Health and Rehabilitation Sciences Publications Health and Rehabilitation Sciences Program

2020

Supports for Migrant Farmworkers: Tensions in (In)access and (In)action

\author{
Susana Caxaj \\ scaxaj@uwo.ca \\ Amy Cohen \\ Okanagan College, acohen@okanagan.bc.ca \\ Sarah Marsden \\ Thompson Rivers University, smarsden@tru.ca
}

Follow this and additional works at: https://ir.lib.uwo.ca/hrspub

Part of the Human Geography Commons, Latin American Studies Commons, Other Legal Studies Commons, Psychiatric and Mental Health Nursing Commons, Public Health and Community Nursing Commons, Public Health Education and Promotion Commons, Rehabilitation and Therapy Commons, and the Social Work Commons

Citation of this paper:

Caxaj, S., Cohen, A. and Marsden, S. (2020), "Supports for migrant farmworkers: tensions in (in)access and (in)action", International Journal of Migration, Health and Social Care, Vol. 16 No. 4, pp. 557-571. https://doi.org/10.1108/IJMHSC-03-2020-0017 
International Journal of Migration, Health and Social Care

\section{Supports for Migrant Farmworkers: Tensions in (In)access and (In)action}

\begin{tabular}{r|l|l|}
\hline Journal: & International Journal of Migration, Health and Social Care & $\begin{array}{r}\text { DOI:10.1108/I } \\
0017\end{array}$ \\
\hline Manuscript ID & IJMHSC-03-2020-0017.R1 & \multicolumn{2}{c}{ Journal inform } \\
\hline Manuscript Type: & Academic Paper & $\begin{array}{l}\text { social support, support actors, migrant agricultural workers, access, } \\
\text { inclusion, support needs }\end{array}$ \\
\hline Keywords
\end{tabular}

\section{SCHOLARONE} Manuscripts 


\section{Supports for migrant farmworkers: tensions in (In)access and (In)action}

\section{Structured Abstract:}

Purpose: This study examined the role of support actors in promoting or hindering access to public services/spaces for migrant agricultural workers (MAWs), and, to determine the factors that influence adequate support for this population.

Methodology: Employing a Situational Analysis methodology, we carried out focus groups and interviews with 40 support actors complimented by a community scan $(n=28)$ with public-facing support persons and a community consultation with migrant farmworkers (MFWs) $(\mathrm{n}=235)$ Findings: Two major themes were revealed: (In)access and (In)action, and; Blurred Lines in Service Provision. The first illustrated how support actors could both reinforce or challenge barriers for this population through tensions of: "Coping or Pushing Back on Constraints," and "Need to find them first!" Justification or Preparation? Blurred lines in Service Provision encompassed organizational/staff's behaviours and contradictions that could hinder meaningful support for MFWs revealing 2 key tensions: "Protection or performance?" and "Contradicting or reconciling priorities? These 4 tensions revealed a support system for MAWs still in its infancy, contending with difficult political and economic conditions.

Implications: Service providers can use research findings to improve supports for MAWs. For example, addressing conflicts of interests in clinical encounters and identification of farms to inform adequate outreach strategies can contribute to more effective support for MAWs.

Value: This research is novel in its examination of multiple sectors and both formal and informal actors involved in MFWs' support that can inform more comprehensive readings of the health and social care resources available to MFWs.

\section{Keywords:}

Social support; support actors; migrant farmworkers; access; public services; inclusion

\section{Article Classification:}

Research Article

\section{INTRODUCTION}

Tens of thousands of migrant workers enter Canada to work in agriculture each year. The majority of these workers participate in the Seasonal Agricultural Workers Program. Representing bilateral agreements with 11 countries of the Caribbean and Mexico, these positions are available to workers for a maximum of 8 months in 1 year. Yet many migrant agricultural workers (MAWs) participate in the SAWP for decades (Hennebry, 2012). Experiences of marginalization, segregation, and limited access to health, social, and legal services have been well documented among this workforce (Basok et. al, 2014; Horgan \& Liinamaa, 2017). These challenges are significant because they are experienced by a group who 
are uniquely susceptible to workplace injuries, workplace violence and harassment, medical repatriation, and exploitation (McLaughlin et. al 2014) Thus, it is important to uncover what social supports are made available to this population, and the degree to which these supports meet (or could meet) this groups' needs.

The social support needs of migrant agricultural workers are best understood within the context of their everyday realities. The nature of the SAWP creates conditions in which workers' permits are tied to a specific employer who has the power to either recommend their continuation in the program (by virtue of a naming system) or dismiss them with no chance of appeal (Preibisch, 2010). Furthermore, fear and awareness of deportability (Basok et. al, 2014), all within a larger context of global inequity, contribute to a climate of coercion for these men and women, that make it difficult for them to seek help, assert their rights, or insist upon safe and healthy workplaces (AUTHORS, 2019).

Barriers to workplace safety, medical care, and legal protections are often exacerbated by dependence on an employer for transportation and translation, lack of familiarity with the Canadian system (Hennebry et al., 2016; AUTHORS, 2020), and geographic and social isolation from the wider community (AUTHORS, 2016). Furthermore, many migrant agricultural workers face language barriers, exclusion from federally-funded programming, lack of adequate confidentiality in medical settings, financial/insurance coverage barriers, and difficulties in accessing follow-up care (AUTHORS, 2018; Salami et. al, 2016; Robillard et. al, 2018). Such vulnerabilities profoundly shape MAWs' social support needs and raise the question: how can support providers address these challenges?

Here, we report on our research focused on social support roles for MAWs in the Okanagan region of British Columbia,Canada, a top destination for SAWP workers in the province, second only to the Fraser Valley. The Okanagan context, known as a touristic, mountainous, 'wine country' destination, in which public health and social care services are not comparable to larger metropolitan systems, creates a unique context for migrant agricultural workers, in which discourses of Whiteness, rurality and leisure may construct this population as invisible (Aguiar et. al, 2010; AUTHORS, 2020). We had two specific study aims: (1) to examine the role of support actors in shaping workers' needs and; (2) to determine the gaps, challenges, and opportunities that influence the development of adequate support for MAWs.

\section{SOCIAL SUPPORT NEEDS AND BARRIERS AMONG SAWP WORKERS}


An important resource for wellbeing (Hynie et al., 2011), social support exists along a continuum based on the degree to which one's needs are (or could) be met by others (Lakey and Orehek, 2011). Encompassing several dimensions (i.e., emotional, instrumental, informational, appraisal) (Finfgeld-Connett, 2005; Langford et al., 1997), social supports are provided by both informal (e.g., neighbours and community members) and formal actors (e.g., service providers) (Guruge et al., 2015). For immigrant populations, social support is largely culturally and socioeconomically mediated and varies depending on the lived realities of particular groups (Stewart et al., 2008). For migrant agricultural workers, social support needs and challenges inherent in seeking this help, are highly complex.

First, migrant agricultural workers work in one of the most hazardous professions yet have unique obstacles to accessing medical care. For racialized and temporary status populations, a heightened risk of workplace injury, discrimination, harassment, and repatriation exacerbate the risks encountered in agriculture. Given that MAWs, particularly in the Canadian context, may rely on their employer for assistance in accessing medical care, transportation, and translation, workers are often disadvantaged in seeking appropriate medical support. Prior research indicates that migrant agricultural workers experience employer-gatekeeping and mediation that can contribute to inappropriate care plans or diagnoses, and even, medical repatriation. This workforce may also fear reporting medically sensitive conditions and symptoms since their health status may be shared with an employer, jeopardizing their job status, and consequently, their position in the SAWP (Hennebry et. al, 2016). Furthermore, limited initial access, comprehensive care, or medical follow-up can present challenges to workers' legal entitlements, especially in regards to workplace injury compensation (McLaughlin et. al, 2014). Given these barriers, scholars have noted the need for different models of primary care, including mobile clinics and targeted programs that better anticipate access barriers for care for this population (Cole et. al, 2019). Furthermore, the importance of legal community clinics and informational campaigns have also been noted. Yet in many regions, these services and initiatives remain limited or non-existent (Rodgers \& Drolet, 2018).

Second, MAWs are often both geographically and socially isolated. Typically residing on their employer's property, accommodations are often crowded, located in amenity-poor districts, and off-route from public transportation. Most MAWsdo not have personal vehicles, and thus, rely on their employer to take them to the grocery store and access other amenities and services 
(AUTHORS, 2019; AUTHORS, 2020; Weiler et. al, 2016). Thus, this workforce is uniquely challenged in establishing networks of support off-farm. When SAWP workers are able to access public spaces, several researchers have noted that they often face racist surveillance and intolerance (Salami et. al, 2015; Sharma, 2001). The gendered and racialized segregation of this workforce may also create further challenges to camaraderie and emotional support among worker cohorts. Furthermore, the limited privacy and space afforded to workers in their accommodations, can make it more difficult to speak up about their legal rights and entitlements, especially when hierarchical workplace dynamics are strictly enforced (Perry, 2018). Our work mapping the support provided by the volunteer sector in particular, suggests that outreach to farms, community-building events and activities, as well the provision of third-party translators may help address some of these barriers (AUTHORS, 2020). Yet a lack of systematic infrastructure to deliver these services may limit the effectiveness of such initiatives. But some MAWs do connect with various informal actors, such as church groups, local business owners, volunteers, and community members (Preibisch, 2004), some of whom may help workers' understand/defend their rights. Given the various gaps in formal services and access to such services, community lay workers, informal volunteers, and community workers can make an impact on this population's ability to better understand health and safety information (OrtegaVelez et al., 2016), and access to medical care (Sexsmith, 2017) and basic information about their rights and entitlements (Rodgers and Drolet, 2018).

Third, SAWP workers have tied work permits allowing them to work for only one employer, and in order to return in subsequent seasons, they must be 'renamed' by their boss. These factors provide an inordinate amount of power to the employer and create further challenges for MAWs who wish to assert their rights and entitlements (Rodgers \& Drolet, 2018). This precarity is exacerbated by limited proactive enforcement of housing conditions and a reliance on complaint-driven processes that are often not accessible to workers (Vosko et. al, 2019). With a looming fear of deportation or expulsion from the program, many migrant agricultural workers are reluctant to access justice when facing discriminatory, exploitative, or abusive conditions (Orkin et. al, 2014; AUTHORS, 2018; AUTHORS, 2019). While as of 2019, migrant agricultural workers are eligible to apply for an open work permit (employment not tied to a particular employer), workers are required to find another employer under the SAWP, a difficult feat. As a result of such challenges advocates have called for this workforce to have 
immediate access to permanent residence, a status that will make it easier for this workforce to assert their rights and refuse unsafe work conditions (Harris, 2020). Others have suggested that more direct lines of communication and engagement with MAWs in oversight mechanisms, would also enable workers' to access supports and protections that can keep them healthier and safer in the workplace (Migrant Worker Health Expert Working Group, 2020). In the meantime, settlement services related to migration status are often not available to this population.

Despite the many barriers, MAWs do both build and access social support. For instance, familial ties are important sources of social support, and among transnational families, can be a mechanism to maintain cultural identities and children's wellbeing (Dominguez and Lubitow, 2008). Yet MAWs, as 'breadwinners', are chronically separated from their dependent family members due to their participation in the workforce, so familial support is often limited to telephone and internet communication. Long-term separation from family and loved ones can take a toll. Research with Mexican MAWs in the United States suggests that MAWs and their families experience "chronic, concrete, and ambiguous" grief because of worry for their loved ones and periods of continuous and repeated separation (Solheim et al., 2016). Likewise, research with 75 Mexican MAWs traveling back and forth from Canada and Mexico and their spouses revealed several challenges experienced because of the separation. Psychological strain and tension was identified both among parents, as well as physical and mental health challenges for children of these workers (McLaughlin et al., 2017). So despite the importance of familial support, temporary migrants may face unique strains on these relationships as a result of familial separation; this can contribute to feelings of shame, isolation, and uncertainty within families (Bernhard et al., 2009)

A critical issue in terms of understanding supports and protections available to migrant agricultural workers is that the SAWP is premised on an assumption that employers represent a reliable form of support for MAWs (e.g. enabling access to healthcare) (McKarney, 2013) and that supporting MAWs represents a 'win-win' for employers and employees alike. Yet, contradictions in this position have been documented. For instance, MAWs have endured a historical lack of standard legal protections, including the right to organize in some jurisdictions. When this exclusion was challenged in the Supreme Court of Canada, parallel legislation was enacted designed specifically for agricultural workers, but with significantly less protections than those provided to other workers (e.g. no right to strike or exclusive bargaining). The longevity of 
this decision has entrenched the second-class status of all agricultural workers in terms of the capacity to form strong unions (Ontario (Attorney General) v. Fraser, [2011] 2 SCR 3). Prior research also suggests that consular officials, MAWs official representatives while in Canada, may side with employers in disputes and are not trusted by workers (Weiler et al., 2016; AUTHORS, 2019; McLaughlin et al., 2017). These examples suggest that MAWs do not see government authorities or employers as resources for support, particularly because of the coercive context that MAWs navigate. Despite calls for improvements to employer monitoring and complaint regimes, and demands to address SAWP workers' precarious status (Parliament of Canada,, 2016), no significant changes to the program have been made .

\section{METHODOLOGY \& FRAMEWORK}

We sought to examine the role of support actors in meeting migrant agricultural workers' needs. Furthermore, we wished to uncover the challenges and opportunities to improve social support for this population We defined social support actors as government staff, public service professionals (including clinicians), non-profit workers, civil society advocates (including labour association representatives), volunteers and other community members (e.g. local grocers) who are either officially mandated to, routinely engage, or have the potential to provide access to services that can improve workers' health, access to justice, or social wellbeing.

Our research was informed by prior research with MAWs in which we identified various challenges, and consequent priorities for support for this population (AUTHORS, YR; AUTHORS, YR). These prior findings were mobilized by stakeholder engagement, including public consultations with MAWs $(\mathrm{n}=235)$ and an environmental scan with relevant front-facing service providers $(\mathrm{n}=28)$ (Graham, Evitts \& MacLean, 2018). Through these activities, we also sought feedback on the parameters and lines of inquiry of our current study.

Following this initial work, we carried out participant interviews and focus groups with individuals who were part of workers' support network, through a process of first recruiting central persons of interest (informed by our environmental scan), and then snowball sampling, Most individuals were able to recommend several relevant people for us to interview. We employed a situational analysis methodology, a post-structural reading of a grounded theory approach that is premised upon, and enables opportunities to explore structural, contextual, and interpersonal factors that shed light on a phenomenon. This approach guides the researcher to focus on processes, contradictions, and discourses that allow readings of complex and messy 
environments (Clarke, 2005). Given our interest in multiple sectors and actors occurring simultaneously at local, provincial, and national contexts, such an approach was fitting.

All participants $(n=30)$, whether in focus groups $(n=25)$ or 1 -on-1 interviews $(n=5)$ provided written consent for sessions to be audio-recorded and transcribed. Individual interviews ranged from 45 to 85 minutes and included participation from formal and informal sectors (see table 1). Interview guide questions included grand-tour questions such as "what is your role in supporting MAWS?, or how do you think your organization can best support MAWs?" and several probes, such as "how do you address experiences of isolation, or employer mediation, or language barriers among this population?"

Table 1: Participants' roles

\begin{tabular}{|l|l|}
\hline Government and/or affiliated associations & 5 \\
\hline Non-profit/public agency staff & 10 \\
\hline Community advocates/volunteers & 15 \\
\hline
\end{tabular}

Employing situational analysis, we engaged in several mapping exercises to make sense of our data (Clarke, 2005). These activities afforded the research team different opportunities to identify processes and factors informing ideas of interest, such as social discourses and actors involved (through ordered mapping), major points of debate and the spectrum of perspectives inbetween (through positional maps), and the constellation of concepts, ideas and actors that constitute an environment/community of interest (through social worlds maps). Each of these processes was done in teams, and each author and 1 research assistant was involved in reviewing transcripts and audio-recordings, ensuring that each interview was analyzed by at least 2 members of the team, for the purpose of consensus-building and capturing the richness of each transcript. At the unit of each transcribed interview, transcripts were scanned for barriers, enablers, opportunities, challenges and examples of social support for MAWs and also summarized to capture broader impressions of each unit of data collection. In addition to work done as individuals and in dyads, the full research team met several times over a 2-year period to collaboratively develop an overarching analysis. The final framework was developed by the first author, and then confirmed and further refined by each author for the purpose of writing up results. Each participant has been given a pseudonym to maintain their confidentiality. 
Our findings revealed 2 major themes encompassing four key tensions, that defined the actions and roles of support actors and illustrated gaps, challenges and opportunities in this regard. Overall, these tensions revealed a support network for MAWs largely in its infancy, both constrained and enabled by various political and economic factors.

\section{(In)Access and (In)Action}

This first theme revealed two key tensions in how support actors identified or addressed barriers to supporting MAWS. Yet practices that normalized these barriers often reinforced gaps in support, and even justified inaction in the delivery of services.

\section{Coping or Pushing Back on Constraints?}

This tension illustrated support actors' responses to material constraints and the degree to which they accepted or actively challenged these constraints to assist workers. Constraints included limited staffing, and limited resources. A notable barrier for settlement organizations in particular was a dependence on federal funding, which largely required them to focus their support services on permanent residents. Some individuals simply accepted these constraints, which had the effect of normalizing inadequate services. Lucinda, for instance, reflected on the factors that made MAWs a 'hard to reach population.' Yet when probed further about why services made available to MAWs, through an 'open door policy,' had not been well attended, she noted:

Because, again, when they're out in the farms, it's so hard to get information to them . . our lack of resources to be able to really connect effectively with workers. And we often look to agencies like [local volunteer group] - to help us to get the information out to them. Um, because we don't really have that information, to be really honest. Um, and because it's - it hasn't been an area that we've been mandated to work with--um, we haven't done as much in that regard, because we're sort of at max capacity at the moment. . . Cause, you can imagine, also if we start advertising--it could open up something that we're not able to really--serve properly.

Other social support actors also described the difficulties of serving this particular population. Many noted external barriers, but when probed further as to how to engage with this group, they expressed doubt about whether the organization had the skills (information), funding, mandate, capacity, or motivation to provide support to this population. Several immigrant settlement staff, like Lucinda, looked to volunteers to fill the gaps that largely mirrored their organizations' 
limitations. Other barriers typically identified by participants included an organization's "banking hours;" distance from farms; workers' isolation and limited access to transportation. There was a consensus that such barriers were largely responsible for limiting workers' access to services.

Given the documented prevalence of barriers related to language trust, accessibility, and suitability of supports, we prompted participants to consider how they addressed these challenges. Echoing other service providers' accounts, clinicians often revealed a complacency with current practices, even when they resulted in substandard care for MAWs. For instance, several clinicians discussed using non-verbal communication or rudimentary Spanish to communicate with workers as a sign of innovation or ingenuity, rather than reflecting on how such practices could hinder adequate care. Often, service providers did not consider making use of third-party translators, even when their employers had specific protocols to enable these services. Clinician Gary described his process for dealing with MAWs with language barriers as follows:

And so, just by looking at the card, and actually, it says on there, I think, something to do with farm work or something - Immigrant Worker Board, or something like that. . . obviously the names of the workers get to be a little bit easier to identify. They come with a translator, which is quite nice [emphasis added]. And so, yeah, it's pretty easy to tell who's who. And actually, I see quite a few of them [migrant farmworkers]. Gary, like many other clinicians, reported systematically sharing medical information with a 'translator', who was likely the worker's supervisor or boss. For instance, when he was asked whether he knew who this translator was, Gary responded: “ I-I don't, because that was-I never asked that question. I don't know if it was a family member that spoke English, or a coworker ... or maybe an employer ... " Such reflections, which were echoed by other clinicians, indicated a lack of awareness of the power dynamics that could hinder workers' access to comprehensive health services, that by virtue of not being identified, remained unchallenged.

Clinician Stuart similarly discussed a normative practice of including employers in MAWs' health care decisions:

Stuart: ... I do recall, a situation where they basically had [symptoms] and [it was] questionable what was going on. They did some preliminary tests here, and they decided 
probably better just to return to Mexico ... and probably follow it up with their own physician in Mexico.

Researcher: Okay. Can you tell me about how that- the worker was kind of included in that decision?

Stuart: Uh, I think it's a decision that they made between the supervisor, the employer, and the individual.

These missed opportunities to address barriers also revealed an approach in which workers, rather than service systems, were seen as lacking. Through the lens of exceptionalism, any accommodation, regardless of its inadequacies, could be viewed as going above and beyond, rather than substandard or inappropriate.

Yet some support actors described incidents of challenging normative practices, and pushing for improved supports for this population. Volunteer advocates, for instance, reported employing more deliberate actions to challenge constraints in the supports available to MAWs. Yet because of their limited capacity, informal support actors often described their actions in terms of 'putting out fires'. Formal support actors discussed different strategies to collaborate with other organizations or governments and build capacity to reach out to communities to leverage limited resources. Typically, this was at the level of contemplation, and the potential solutions broached in conversation had not yet been tested in the field. One exception to this was shared by government agent Carlos. He recounted actions his department had taken to address long-standing substandard housing concerns faced by workers through documentation and advocacy to government departments:

... all the data we gathered in the past two years, and the pictures, and we send those pictures [of substandard housing] to every single minister. . it's amazing because it was a lot of work, but, as I told them, the whole team [department], [we] decided not to take it personally [the treatment of workers], but to write down every single thing we saw.... Create hard data and put it in the-in the interest of [community within their jurisdiction]

\section{"Need to find them first!" Justification or Preparation?}

This tension focused on participants' responses to perceived distance of workers, whether geographic, cultural, or social. Participants' accounts revealed both motivations to engage with workers, and justifications for not reaching out to workers. Underlying both of these positions 
was a recognition that workers remained significantly isolated, with little access to anything outside of their work domain. Judy, for example, noted: "because many of them, they work, and they go home, and they shop. And those three things, those are the only things they do. To have a balanced life here, they should also enjoy—recreation [and a social life]." Awareness of workers' segregation, and difficulties accessing services and other public spaces helped support actors understand a significant need, but also posed significant barriers. Most concretely, several participants disclosed that they lacked knowledge necessary to locate MAWs. Sometimes, support actors recognized that their outreach strategy was limited, and would require a more sustained effort to more meaningfully help workers. Alicia reflected:

And, you know, for us to be able to effectively offer them services, we would have to actually physically go out there on the farms, which we haven't done. Or at least haven't done to a large degree. We've done it for workshops and one-off sort of events, but we don't do it on a regular basis.

For several formal support actors, it was not a matter of simply locating workers and being committed to outreach; interviews also revealed apprehension about how to engage with MAWs due to larger community dynamics, even though they acknowledged that workers were unlikely to be able to independently reach out to them. Service provider Kathy stated:

We also find that there are some that — maybe some employers — that would find us to be a threat more so than help. . . So, I mean, there is a need out there. . We just don't know if we can actually go in and ask questions. We don't want to create controversy or ill feelings with employers. Because we do need temporary foreign workers to come in and work on these farms, right? .. And [name of town]'s a small community. . . And we know some of those employers, because they're previously clients.

For Kathy's organization and others, fear of conflict within the community was a significant deterrent to reaching out to workers, even amidst a context in which workers were unlikely to access services on their own. Yet beyond knowing where to find workers, formal support actors also expressed hesitation to actively include MAWs, because of the implications it would have on the sustainability of their organizations. Barbara reflected:

Again, the reality is we can't afford to ... Um, we don't market to, um, international students [workers without a clear path to permanent residence]. We don't market to the agricultural workers. We don't market to, actually, many temporary foreign workers. , , , 
just because the fact that we could be overwhelmed, and then we can't provide the quality of service that we would like to. . . And then do substandard services. [Sighs] ... So, we try to introduce and invite [them] to the things that we have the capacity to do. . .

The commonly expressed barrier of 'we need to know where they are first,' may represent an honest understanding of a barrier, but could also be seen as hesitation to deliver boots-on-the-ground support for MAWs, influenced by limits on both funding and capacity. Such conditions often meant that MAWs were only passively included in programming, but because little attention was paid to 'finding them first,' (e.g. outreach), symbolic gestures (e.g. events in which all are welcome) typically yielded limited uptake among MAWs. The fear of creating conflict in the community, and the difficulties locating workers in the community has not been documented in prior literature on this topic. This phenomenon suggests an important service delivery consideration, including the need to account for 'finding workers' in both planning programming and in the training of personnel.

Some volunteer and union organizations described purposeful and creative strategies to reach workers. These activities were typically not conducted systematically and tended to be improvisational because of limited resources/capacity characteristic of volunteer based activity, as well as the unpredictability of a population with limited control over their day-to-day schedule. Community organizer Caleb explained how this planning often evolved:

We were unsure how many people were coming. We had maybe 30 people on the list [confirmed] that said they were going to come, and we knew pretty well. And so, we planned for about 30 to 40 , and then the day of, umm...there was maybe 150 people that wanted to go. Maybe 200. Umm... and so, um, yeah, we just kind of scrambled ... and [other volunteer] found a bus, like a full-sized bus and drove it up. And everyone just kind of like - if they were coming in one car, they started coming in two or three cars. Umm...yeah, I mean, we probably got 100 people there. So, we didn't have to turn too many people away.

New challenges emerged because of these activities. For instance, building rapport with workers could be a complicated process. Indigenous workers or groups with a history of war or violence in their countries of origin could be particularly wary of the intentions of individuals approaching them. Likewise, some workers were accustomed to only dealing with individuals wanting to sell them something, making it difficult to trust offers of friendship or solidarity. Yet 
approaching workers could also be a breakthrough in an otherwise indifferent or exclusionary host community. Volunteer organizer Jessica explained:

I think people who speak Spanish—might start up a conversation, especially in public spaces, like at the public markets.... . But on the flip side, I also heard a lot of comments about people experiencing racism and discrimination in public... I had one instance where I went up to some Jamaican guy, saying hi, and speaking to them about [volunteer organization]. And they were just so shocked that I talked to them. They're like, “Oh my god, thank you! No one ever talks to us. They just look at us like we're so dirty. . . Just thank you so much for acknowledging that we exist. . I remember that that really struck me.

\section{Blurred Lines in Service Provision}

This theme revealed the ways that support persons inhabited contradictions because of jurisdictional boundaries, conflicts of interest, questionable practices, and larger political aims. Nonetheless, some participants also discussed strategies to face these contradictions in order to engage in more meaningful support.

\section{Protection or Performance?}

In several interviews, participants claimed that they were the true supports or protectors of MAWs. Yet an analysis of these accounts suggested a level of image crafting or 'performance' which raised questions about the informants' true commitment or capacity to support MAWs. Contradictory motivations for instance could both contribute to or detract from meaningful supports for this population. To illustrate, among government agents, a desire to maintain a favourable image of agricultural industry partners (including employers) often impeded their ability to meaningfully address hardships or challenges faced by MAWs. For instance, one government representative dismissed claims of housing challenges, labour, or occupational health and safety standards faced by workers, other than in a 'handful' of cases, even when evidence of the frequency of such incidents was presented to the participant. Furthermore, this same informant deflected from such incidents by attributing labour and employer conflicts largely to MAWs' cultural differences and inability to trust systems in place, rather than because of employer misconduct or inadequate regulation.

Several formal government support actors also discussed the difficulties of providing 
services to workers given the high ratios of workers to support staff. Based on their accounts, this roughly averaged 1 government support person for every 1000 workers. Nonetheless, these same participants suggested that they could reach all workers, and one government agent even challenged the utility of partnerships with non-governmental support groups, suggesting that all the support needs of MAWs could be satisfied solely through their department. When probed further about supports in the community, this participant suggested that it did not make sense for workers to reach out to support groups because all their needs were addressed by the contract (met by employers or government):

Because the contract basically says the employer has to do these things - -and the government does these things. . It's all in the contract. "Who can take me to the doctor if I'm sick?" because the employer has to do that. Or "How do I get my groceries?" because the employer has to do that, to take them to do the shopping, you know? ... Those things that are basically covered under the SAWP. So, you really don't have that headache ... that they need people [support organizations] to help them figure out how to get that done.

Formal government actors illustrated another example of this tension when presenting the scope of their services comprehensively, yet then discussing much of this help as a charitable act or 'extra' rather than one that fulfilled an official mandate. A government official stated:

Samuel: Yes. Uh, we're probably the only [government role of jurisdiction] that does all this, because we're the only province that does not have a structure like F.A.R.M.S [Ontario organization that coordinates the processing of requests for foreign seasonal agricultural workers] that are pretty big organizations that supply these services, so we are practically their F.A.R.M.S of BC. So, regarding finances, we receive all their T4s. We send them out to them. We help them with their T1s, CPP, maternity, paternity, uh, pensions. When there's somebody deceased, we help the family members to get the pension from the government. Uh, what else? Yeah, sending their taxes...

Researcher: Your official role is to assist workers doing all of those things?

Samuel: Excuse me?

Researcher: So, your official role would be to assist workers in doing all of those things? Samuel: No. My official role is to protect them . . . That's, uh, I would say it's extra. 
Such positions on what was considered 'extra' had real implications for MAWs, given that so many of them struggled to secure benefits, and a large portion, faced consequences as a result of lacking the knowledge to meet tax and other reporting requirements. This emphasis helped to construct an image of the support actors as 'helpers' but still maintain a distance from addressing the immediate issues faced by workers.

For advocacy groups and labour organizations, the tension of protection versus performance often manifested as doubts about the extent to which their position as ad hoc service providers could address the larger problem of inadequate protections for MAWs and necessary policy reforms. Yet for some, it was only by accompanying workers in more routine or recreational activities that questions around rights, entitlements, and mistreatment were raised. Caleb reflected:

People just want to do something, anything. Go to the beach. ... Just like, from there it expands a little bit, and you know. . . Like, there's those kinds of serious questions. But those only ever happened after they asked me to drive them to a dance or something like that, you know?. . And it almost inevitably does, because there's issues at every single farm, you know? People obviously have things that they want to ask, like "Is it legal for them to not give me a mask when I'm spraying?" or "Do they have to-do we have to pay for housing?

At times, these questions could provoke feelings of complicity and even helplessness, because workers' questions reflected a clear dismay and bewilderment of their treatment:

[Workers ask me] 'Why do people not care about us?" You know, it's like, "Why are we being left in the backwoods in some shitty shack?' . . It's kind of like, 'Why does Canada not care about us?' you know? And yeah. I don't know how to answer that. Competing or Reconciling Priorities?

Most participants' accounts revealed competing interests that shaped the type, degree, and quality of support provided. Alicia, a formal service provider actively working on legal issues faced by MAWs, suggested that some grassroots groups' political motivations could contrast with the immediate needs of MAWs:

... you never have control over how a reporter's going to present a story, and that can come into play when there is a legal process underway. You know, while I understand that there is a very dire need for political advocacy around issues, but you know, people 
under these programs, I think sometimes, because of a lack of capacity and not really knowing how to help, some groups might refer people to the media, or want them to speak publicly when they're not necessarily going to be assured protection, you know? So an organization's larger mandate for political advocacy could be at odds with an individual worker's need to get the best legal compensation because of mistreatment or injury.

Funding requirements were also not only constraints on services and outreach strategies among support actors, but also could create competing priorities for support actors, who instead of thinking about MAWs' needs, first considered how affordable or 'fundable' service might look on paper. While operational costs are always a challenge for support actors, the fact that some participants' accounts sometimes focused on the difficulties of 'pitching' funding suggests that organizations may be pre-emptively excluding MAWs from their programming because they are viewed as an inherent financial liability, ironically, due in part to their high need and isolation.

Similar to experiences with translation issues discussed above, decisions about how to report workplace injuries were often directed by the clinician's relationship with the employer, rather than the injured worker. Clinician Ken discussed how he took direction from an employer and decided not to report a workplace injury to the workers compensation agency:

Generally, employers don't like people to go through WCB [the Workers Compensation Board] if they can ... and so, they kind of just put it through on Cowan [workers' private insurance], kind of attitude. And it's less paperwork, it's less headaches just to do it that way.

Since these processes deny workers the necessary documentation to put forward a claim for wage losses related to their workplace injury, clinicians adopting these practices were clearly at odds with providing the best support for MAWs. In contrast, some clinicians' aims of efficiency and 'less paperwork' could result in fewer out-of-pocket expenses for workers. The desire for expediency and less overhead was an interest that had positive consequences for MAWs. Whenever clinics/hospitals would not directly bill insurance providers, workers would have to pay out-of-pocket and apply for reimbursement, a process that workers reported to be unreliable.

Some participants took on roles as support actors, despite the effort or time it took away from their primary role. For example, business owners whose primary relationship with workers 
was to sell goods and money transfer services reported assisting workers with translation or accompaniment to a hospital/clinic, providing assistance navigating or understanding services, mediating conflicts with employers, or organizing recreational events. Support by these participants however, could be complicated. This was illustrated by Eugenia's description of an event that some MAWs attended:

... [a] few that have the time off, they did arrive and we had pozole [traditional Mexican soup] and stuff like that, and they loved it . . . but the thing is, is they had said to them [organizers], Oh, this gets kind of expensive." I said, "Look, you have to think. Things cross two borders to get here. It's not like we're just going to go in Mexico and buy it from the market on the street." I said, "Here's two borders. You pay duty on things, and it's just crazy." ... Yeah, so it's a hard situation. . .

In this sense, business owners were faced with a dilemma of being perceived as, and genuinely requiring, a profit for some services delivered, while also providing a rare type of support within MAW communities. So efforts to build a sense of community could become tainted by mistrust among workers if they sensed that the real motivation of such a person was financial gain.

\section{DISCUSSION \& CONCLUSION}

We identified 2 larger themes encompassing 4 key tensions that both fueled and stagnated support roles for MAWs. Through the theme of (In)access and (In)action we were able to identify 2 tensions: (1) Coping or pushing back on constraints and; (2) "Need to find them first!'Justification or preparation? This first tension illustrated the ways in which support actors may be active in addressing barriers, or, may be complicit in internalizing existing obstacles faced by workers, and ultimately widening gaps in service access and provision. "Need to find them first" revealed instances in which support persons either implemented active outreach strategies to include migrant workers in their programming, or relied on passive service provision that made existing services mostly inaccessible to this group. Overall, the theme of (In)access and (In)action revealed various factors (e.g. motivations, dedicated resources) that determined the level of accessibility and availability of services for migrant agricultural workers.

Prior research indicates that many support persons are keenly aware of the barriers faced by MAWs (Salami et al., 2016) Our own work, focussed on informal volunteer contributions, has shown that some support groups are active in anticipating barriers and bridging connections 
to the community to build meaningful support for this population (AUTHORS, 2020). Yet our findings here indicate that some support actors may also internalize and normalize barriers to access for this population. And furthermore, concerns about an organization's operational spending may overshadow motivations to develop truly accessible services for this population. Prior research looking at mobile clinic programs for migrant workers indicates that academiccommunity partnerships, in which one organization takes the lead on establishing sustainability, may be a model to transparently address organizational financial needs while working towards greater accessibility for migrant workers' support needs (Luque \& Castaneda, 2013). Further research into partnership models to address the unique accessibility and support needs of MAWs, especially within the Canadian context, may help shed light on how tensions identified in this study can be addressed. In addition, greater transparency about the organizational assumptions that may determine service provision can be an important starting point to integrate greater flexibility into support provision for MAWs.

Under the theme of Blurred Lines in Service Provision, we identified two additional tensions: (3) Protection or Performance and; (4) Competing or Reconciling Priorities. Together, these 2 tensions illustrated several contradictions that could limit support for MAWs, but also revealed ways in which some actors were taking up strategies to more authentically offer support to this group. The tension of protection or performance revealed the ways that support persons could invest in a certain image as 'helper,' yet as a result of the contradictory nature of their role or due to limited capacity, could create further challenges when/if they were unable to deliver on these supports. A notable challenge was that if individuals were more focussed on the performance of support, they could create bigger gaps in support available for workers, by hiding crucial gaps in support provision. The tension of competing or reconciling priorities highlighted how different aims among support persons, including political advocacy, expediency, costeffectiveness or financial profit could either coalesce or clash with the agenda of providing effective support for MAWs.

Prior research has documented various ways in which supports available to migrant agricultural workers are limited and may be influenced by medical paternalism, inadequate infrastructure, and limited capacity. For instance, prior research has identified the challenges of employer mediation in medical care (Hennebry et. al, 2016), clinician gatekeeping (Hanley et al., 2015; AUTHORS, 2020), and the fear of medical repatriation (Orkin et al., 2014) in threatening 
the privacy, agency, and continuity of care of MAW patients. The shortcomings of government agencies from participating SAWP countries (including Canada), in enforcing and ensuring workers' adequate workplace and living conditions have also been documented, as well as the ways in which rights and entitlements on paper have often not translated into tangible legal, health and social services/supports for this population (McLaughlin et al., 2014; Vosko et. al, 2019). Furthermore, a recent legal analysis (2019) of MAW regimes indicate that bureaucrats flex a great deal of discretion and variance in their work, and this, coupled with unequal power, staff, and resources, creates barriers for rights enforcement for MAWs. Front-line service providers and community volunteers too have limitations in the support they offer, because they may not feel empowered to address root causes affecting workers' wellbeing (Robillard et. al, 2018) and because several gaps in support can only partially and inconsistently be met by volunteers (Rodgers \& Drolet, 2016; AUTHORS, 2020).

Our research adds to this body of work by revealing actions and motivations of certain individuals and organizations to be seen as a 'helper' that may conceal or fail to address conflicts of interests, complexities or limitations in support delivery for MAWs. Furthermore, the practicalities of a service (e.g. expediency, cost-effectiveness) was sometimes leveraged to support workers, by for example, direct billing, or, disadvantage workers, by for example, assuming that an employer was a suitable translator. A misalignment with MAWs' support needs and organizational priorities, speaks to the need to both identify organizations that can be more responsive to MAWs,' and when possible, work with service providers to identify true 'win-win' possibilities that enhance service provision for this population. While MAWs' racialized segregation (Horgan, Liinama, 2017), and need for greater rights and protections (Dias-Abey, 2018; Preibisch, 2004) are well-documented realities, our research highlights the more relational, mundane, and positionally complex dynamics that often shape support actors' work. Our research suggests that for some support actors, a sense of relational accountability can both fuel and paralyze their capacity to support MAWs. So the diversity within the MAW population as well as the unequal power relationships that are rampant in the agricultural sector and in the wider community (Preibisch, 2010) must be accounted for in the development of more comprehensive and authentic social support initiatives for this population.

In conclusion, by examining the role of support actors, and the challenges and opportunities for adequate supports for MAWs, we were able to identify processes that 
contributed to (1) (In)Access and (In)Action, representing a spectrum of stagnation and proactiveness in support delivery and (2) Blurred Lines in Service Provision, representing the possibility of oppositional/contradictory or alternatively, strategic approaches to support, on the basis of roles and positions taken up by support persons. By articulating these tensions and limitations of current supports for migrant agricultural workers we do not intend to malign our participants, rather, they reveal larger political factors that influence support actors' motivations, and suggest important points of intervention to strengthen supports for MAWs. For instance, training to address medical paternalism, initiatives to address jurisdictional inconsistencies, and proactive outreach strategies to build relationships with migrant worker communities may all help to strengthen the support made available to MAWs. Yet until the funding climate and the role socialization of service providers across various sectors (e.g. health, legal, settlement) is altered to explicitly account for MAWs, support will be inherently limited. Further, more attention to the political implications of who is considered a 'support' for MAW is needed in order to consider the systemic, coercive and vulnerable social positions that MAWs so often navigate.

\section{Acknowledgement:}

Thank you to Nada Alaidarous for helping with the formatting of this article and Yazmin Davila, Laura Prada and Monica Good for volunteer support with data collection or analysis. Funding for this research was provided by the Social Sciences and Humanities Research Council of Canada through an Insight Development Grant.

\section{REFERENCES}

. Caxaj, C. S. \& Cohen, A. (2020). Best practices and readiness for support provision for migrant agricultural workers: a case of capacity, context and creativity. Health and Social Care in the Community.

Cohen, A. \& Caxaj, C. S. (2018) Bodies and Borders: Migrant women farmworkers and the struggle for sexual and reproductive justice in British Columbia, Canada. Alternate Routes, 29, 90 - 117.

Caxaj, S., \& Diaz, L. (2018). Migrant workers'(non) belonging in rural British Columbia, Canada: storied experiences of Marginal Living. International Journal of Migration, Health and Social Care.

Aguiar, L., McKinnon, A., \& Sookraj, D. (2010). Repertoires of racism: reactions to Jamaicans in the Okanagan Valley. BC Studies: The British Columbian Quarterly, (168), 65-79.

Basok, T., Bélanger, D. and Rivas, E. (2014), "Reproducing deportability: Migrant agricultural workers in south-western Ontario", Journal of Ethnic and Migration Studies, Vol. 40 No. 
International Journal of Migration, Health and Social Care

(In)access \& (In)Action: Migrant Farmworkers

9, pp. 1394-1413.

Bernhard, J., Landolt, P. and Goldring, L. (2009), “The institutional production and social reproduction of transnational families: The case of Latin American immigrants in Toronto", International Migration, Vol. 46 No. 2, pp. 3-31. .

Clarke, A. E. (2005), Situational analysis: Grounded theory after the postmodern turn, Sage, Thousand Oaks, CA.

Dias-Abey, M. (2018), “Justice on Our Fields: Can Alt-Labor Organizations Improve Migrant Farm Workers' Conditions”, Harv. CR-CLL Rev., Vol. 53, pp. 167.

Domínguez, S. and Lubitow, A. (2008), “Transnational ties, poverty, and identity: Latin American immigrant women in public housing”, Family relations, Vol. 57 No. 4, pp. 419-430.

Finfgeld-Connett, D. (2005), "Clarification of social support”, Journal of Nursing Scholarship, Vol. 37 No. 1, pp. 4-9.

Graham, P., Evitts, T., \& Thomas-MacLean, R. (2008). Environmental scans: How useful are they for primary care research?. Canadian Family Physician, 54(7), 1022-1023.

Guruge, S., Thomson, M. S., George, U. and Chaze, F. (2015), "Social support, social conflict, and immigrant women's mental health in a Canadian context: a scoping review" Journal of psychiatric and mental health nursing, Vol. 22 No.9, pp. 655-667.

Hanley, J., Gravel, S., Bernstein, S., Villanueva, F. and Crespo Villarreal, D. (2015), “Central 54 American temporary foreign workers in Québec smalltowns: A portrait of community integration in Canada”, IRPP Study 26, Montreal: Institute for Research on Public Policy, available at: https://irpp.org/research-studies/permanently-temporary/ (accessed 20 January 2020) 
Migration Studies, Vol. 43 No. 5, pp. 713-730.

Hynie, M., Crooks, V. A. and Barragan, J. (2011), “Immigrant and refugee social networks: determinants and consequences of social support among women newcomers to Canada", Canadian Journal of Nursing Research, Vol. 43 No. 4, pp. 26-46.

Lakey, B. and Orehek, E. (2011), "Relational regulation theory: A new approach to explain the link between perceived social support and mental health", Psychological review, Vol. 118 No. 3, pp. 482.

Langford, C.P., Bowsher, J., Maloney J.P. and Lillis, P.P. (1997), “Social support: A conceptual analysis", Journal of Advanced Nursing, Vol. 25 No. 1, pp. 95-100.

Luque, J. S., \& Castañeda, H. (2013). Delivery of mobile clinic services to migrant and seasonal farmworkers: a review of practice models for community-academic partnerships. Journal of community health, 38(2), 397-407.

McKarney, M. (2013), "In Defense of a Livelihood: Ontario Growers and the Seasonal Agricultural Workers Program Debate", available at: https://ir.lib.uwo.ca/etd/1510 (accessed 20 January 2020)

McLaughlin, J., Hennebry, J. and Haines, T. (2014), "Paper versus practice: occupational health and safety protections and realities for temporary foreign agricultural workers in Ontario", Perspectives interdisciplinaires sur le travail et la santé, Vol. 16 No. 2.

McLaughlin, J., Wells, D., Mendiburo, A., Lyn, A. and Vasilevska, B. (2017), “ ‘Temporary Workers', Temporary Fathers: Transnational Family Impacts of Canada's Seasonal Agricultural Worker Program", Relations industrielles/Industrial Relations, Vol. 72 No. 4, pp. 682-709.

Migrant Worker Health Expert Working Group (June 2020). Recommendations for overcoming health challenges faced by migrant agricultural workers during the COVID-19 virus pandemic. Retrieved June 16, 2020 from:

http://www.migrantworker.ca/wp-content/uploads/2020/06/June-9-2020-HCrecommendations.pdf

Orkin, A. M., Lay, M., McLaughlin, J., Schwandt, M. and Cole, D. (2014), "Medical repatriation of migrant farm workers in Ontario: a descriptive analysis", Canadian Medical Association Journal, Vol. 2 No. 3, pp. 391-392.

Ortega-Vélez, M. I., Rosales, C., Gallegos, P. A., Paniagua, A. D. C., Valdez, L. and De Zapien, J. (2016), "Developing a network of community health workers: Improving the lives of 
migrant farmworkers”, Open Journal of Social Sciences, Vol. 4 No. 10, pp. 140-154.

Parliament of Canada (2016), “Temporary Foreign Worker Program”, HUMA 42-1, Ottawa: House of Common, available at: https://www.ourcommons.ca/DocumentViewer/en/421/HUMA/report-4/ (accessed 20 January 2020)

Perry, J.A. (2018), "Living at work and intra-worker sociality among migrant farm workers in Canada”, Journal of International Migration and Integration, Vol. 19 No. 4, pp. 10211036.

Preibisch, K. L. (2004), "Migrant agricultural workers and processes of social inclusion in rural Canada: Encuentros and desencuentros", Canadian journal of Latin American and Caribbean studies, Vol. 29 No. 57-58, pp. 203-239.

Preibisch, K. (2010), "Pick-your-own labor: Migrant workers and flexibility in Canadian agriculture”, International Migration Review, Vol. 44 No. 2, pp. 404-441.

Robillard, C., McLaughlin, J., Cole, D.C., Vasilevska, B. and Gendron, R. (2018), “"Caught in the Same Webs" - service providers' insights on gender-based and structural violence among female temporary foreign workers in Canada", Journal of International Migration and Integration, Vol. 19 No. 3, pp. 583-606.

Rodgers, A. and Drolet, N. (ed). (2018), "Envisioning Justice for Migrant Workers: A legal needs assessment", Vancouver: Migrant Workers Centre, available at: https://mwcbc.ca/downloads/MWC_Envisioning_Justice_for_Migrant_Workers_Report. pdf (accessed 15 July 2019)

Salami, B., Kirova, A., Hegadoren, K., Meherali, S., Chiu, Y. and Nsaliwa, C. (2016), “The challenges encountered by immigrant-serving agencies in addressing the health of temporary foreign workers", Social work in public health, Vol. 31 No. 7, pp. 599-606.

Sexsmith, K. (2017), “ 'But we can't call 911': Undocumented immigrant farmworkers and access to social protection in New York”, Oxford Development Studies, Vol. 45 No.1, pp. 96-111.

Sharma, N. (2001), "On being not Canadian: The social organization of "migrant workers" in Canada", Canadian Review of Sociology/Revue canadienne de sociologie, Vol. 38 No. 4 , pp. 415-439. 
Solheim, C., Zaid, S. and Ballard, J. (2016), “Ambiguous loss experienced by transnational Mexican immigrant families", Family process, Vol. 55 No. 2, pp. 338-353.

Stewart, M., Anderson, J., Beiser, M., Mwakarimba, E., Neufeld, A., Simich, L. and Spitzer, D. (2008), "Multicultural meanings of social support among immigrants and refugees", International Migration, Vol. 46 No. 3, pp. 123-159.

Vosko, L. F., Tucker, E., \& Casey, R. (2019). Enforcing Employment Standards for Migrant Agricultural Workers in Ontario, Canada: Exposing Underexplored Layers of Vulnerability. International Journal of Comparative Labour Law and Industrial Relations, 35(2), 227-254.

Weiler, A. M., Otero, G. and Wittman, H. (2016), "Rock stars and bad apples: Moral economies of alternative food networks and precarious farm work regimes" Antipode, Vol. 48 No. 4, pp. 1140-1162.

\section{Authors Biographies:}

Dr. Susana Caxaj is an assistant professor in the School of Nursing at the University of Western Ontario.

Professor Amy Cohen is faculty at the School of Anthropology at Okanagan College.

Dr. Sarah Marsden is an associate professor at the Faculty of Law at Thompson Rivers University. 


\section{Table 1: Participants' roles}

\begin{tabular}{|l|l|}
\hline Government and/or affiliated associations & 5 \\
\hline Non-profit/public agency staff & 10 \\
\hline Community advocates/volunteers & 15 \\
\hline
\end{tabular}

